\title{
Cardiac Biomarker Levels After a Football Match in Professional Versus Amateur Lithuanian Football Players
}

\author{
Corresponding author: \\ Ali Aldujeli, Department \\ of Cardiology, Medical Academy, \\ Lithuanian University of Health \\ Sciences, Kaunas, Lithuania \\ e-mail: Ali.Aldujeli@kaunoklinikos.It
}

\begin{abstract}
Background: There are very limited scientific data available on cardiac troponin I release after intermittent exercise. To know the different factors that mediate cTnl release after exercise is of concern for scientists. In this regard, our study is based on two major goals: 1) to evaluate the cTnl release in individuals during a sports match; and 2) to understand the impact of the status of the athlete (biological) on the release of individual cTnl.

Methods: A total of 44 players, including "22 adult professional [PFP]: $24.2 \pm 4.5$ years, 22 adult amateur [AFP]: $26.5 \pm 3.6$ years" were involved in a match simulated as real. Successive observations of cTnl release were obtained at different settings such as at rest, pre-exercise, and instant-post-exercise at regular intervals of 3,6 , and then $24 \mathrm{~h}$ post-exercise.

Results: From the obtained results it was observed that the individual highest values were vastly varied, with higher levels of $\mathrm{cTnl}$ release baseline and post-exercise for PFP players as compared to those of AFP (all $p<0.05$ ). Moreover, the cTnl levels were increased (peak post: 0.024 [0.004-0.244] $\mu \mathrm{g} / \mathrm{L} ; \mathrm{p}<$ 0.05). Additionally, the cTnl peak values surpassed the upper limit of reference in $77.3 \%$ of PFP (17 PFP). Conclusions: Our study data results affirm that the cTnl release is highly affected by the status of athletes. The cTnl release is enhanced by intermittent exercise.

Key words: football, troponin I, cardiac biomarkers, exercise
\end{abstract}

Med Res J 2019; 4 (4): 210-215

\section{Introduction}

There is huge interest among scientists in studying the biomarkers released by cardiomyocytes at different levels of physical workout. Cardiac troponins (cTn) have gained great importance among researchers because they are a key biomarker [1, 2]. It is an established fact that many athletes after long-duration exercise have more than the upper reference limit (URL) release of CTn [3]. Some studies have also shown high values for $\mathrm{CTn}$ release among sportspersons, even for short-duration exercise [4], moderate duration [5], and continuous exercise [6]. There has also been an effort to study the different factors that affect the cTn release after physical workouts. Several research works have associated the increase in cardiac troponin I (cTnl) with exercise style [7], individual age [8], high throughput exercises, and long duration [5] and level of physical adaptation to exercise [9]. However, the results obtained in different studies do not cohere with each other.

Different studies were performed on the release of cTn after a physical workout is done on a regular basis, such as weightlifting [10], floorball [11], basketball [12], or marathon running [13]. These research works have inadequate data to be utilised for a significant evaluation. For instance, some studies have improper sampling time for post-exercise [10-13]; some have a poorly controlled condition for evaluation $[11,12]$. Moreover, the athletes monitored in the studies are amateur rather than professional. Since it is an established fact that amateur athletes usually show cTn levels that are detectable after exercise more than the values exhibited by experienced and professional athletes $[9,14-18]$. Similarly, the data is usually obtained from activities that are field based, and post-activity sampling intervals are fewer, which shows data with inaccurate values for cTn release [19]. Simi- 
larly, in some studies, higher values of cTn values have been observed from pre- and post-exercise conditions [8] due to controlled interventions during endurance training. From the literature, it is evident that in adolescent athletes, their immature cardiac muscles result in increased cTn detection after exercise [8, 17, 18, 20]. Therefore, these data obtained are not significant for a better understanding of the cTn release mechanism.

Despite all the mentioned studies in literature, more studies are required to understand the impact of training level on cTn release from a training or athletic status point of view. Full understanding of the cTn release in professional athletes is essential, although some data are available with sample frequency deficiencies [21, 22]. Therefore, it is very important to deal with these issues; hence, a study was designed by hypothesising that among the amateur players and adolescent ones the cTnl release is increased during recovery. The study was designed by employing multiple sampling points within $24 \mathrm{~h}$ after exercise. The release of cTnl monitoring was articulated to observe the effect of a football match among players in a simulated manner similar to a real one. To have comprehensive data, the players of different training levels were selected from among both professionals and amateurs.

\section{Material and methods}

\section{Subjects and design}

A cohort of players of football $(n=44)$ was selected. The players comprised 22 adults, professional football players (PFP) from the Lithuanian A League and 22 adults, amateur football players (AFP) from a local university football team. All the players gave written informed consent for the participation in an imitative football game, and during the first $24 \mathrm{~h}$ after exercise, continuous evaluation of cTnl release was performed. Pertinent information about the study purpose, testing procedures, and possible risks was given to the players and their parents. Furthermore, they were given the liberty to terminate participation at will. This study was given approval by the Research Ethics Committee of the republic of Lithuania. The study complies with the principles laid down in the Declaration of Helsinki, adopted by the $18^{\text {th }}$ World Medical Assembly, Helsinki,
Finland, June 1964, and recently amended at the $59^{\text {th }}$ World Medical Assembly, Seoul, Korea, October 2008.

Table 1 shows the major features of the study cohort. Both AFP had training history lower than PFP and lower current training volume as well (all $p<0.05$ ). The PFP and AFP players' ages were not very different. All the players were scheduled to attend the laboratory for three sessions. However, before attending the first session, all the players were instructed not to do any vigorous athletic activity for at least $48 \mathrm{~h}$ before attending the laboratory session. Instructions were given for maintaining their routine life with a normal diet and their sleeping routine etc. Furthermore, subjects were asked to not take any meal at least $3 \mathrm{hr}$ before the test and avoid any energetic products.

In the first session, a general physical check-up was done, which included height and body weight, measured using Health O Meter 500KL Series Digital Adult Scales. In order to get personal information, a history of players' training and any cardiac problems, a questionnaire was filled in by them in with pre-organised questions. In the first session, to exclude any player having significant cardiac history or pathological electrocardiograph, a 12-lead ECG was done. For determining the VO2max, all the athletes were asked to perform a shuttle run test of $20 \mathrm{~m}$ [23]. The maximal heart rate (HR) was measured by an Acentas team monitoring system (Acentas $\mathrm{GmbH}$, Hörgertshausen, Germany).

In the second round of laboratory visits, two teams were made to play a match. All players were asked to play their game in the position where they usually perform. The players were asked to treat the game as a regular competitive match and perform a similar warm-up as they usually would. FIFA regulations were applied to the played match. To make it possible for all players to participate in the game, every team was allowed to make changes after an interval of $4 \mathrm{~min}$ of the actual game time. By using the Acentas team monitoring system, routine and continuous monitoring was performed for HR during the match. To assess serum cTnl venous blood samples were taken at several stages of the game, i.e. before the game, immediately after (usually $5 \mathrm{~min}$ ), and post-exercise at 3,6 , and $24 \mathrm{~h}$.

The blood samples taken were immediately put in a centrifuge to separate out plasma and serum and then stored at $-80^{\circ} \mathrm{C}$ for later research work. A URL

Table 1. Characteristics of the football players

\begin{tabular}{lccccc}
\hline & Age (years) & $\begin{array}{c}\mathbf{B M I} \\
\left(\mathbf{k g} / \mathbf{m}^{2}\right)\end{array}$ & $\begin{array}{c}\text { VO2max } \\
(\mathbf{m l} / \mathbf{k g} / \mathbf{m i n})\end{array}$ & $\begin{array}{c}\text { Football } \\
\text { training } \\
\text { history (years) }\end{array}$ & $\begin{array}{c}\text { Football training } \\
\text { magnitude } \\
\text { (hours/week) }\end{array}$ \\
\hline Professional football players $(\mathrm{n}=22)$ & $24.2 \pm 4.5$ & $23.5 \pm 3.4$ & $60 \pm 4.3$ & $10 \pm 3.3$ & $20 \pm 2.5$ \\
Amateur Football players $(\mathrm{n}=22)$ & $26.5 \pm 3.6$ & $19.9 \pm 6.1$ & $57 \pm 5.0$ & $6 \pm 4.0$ & $7 \pm 3.2$ \\
P value & $\mathrm{P}=0.1$ & $\mathrm{P}=0.025$ & $\mathrm{P}=0.001$ & $\mathrm{P}=0.02$ & $\mathrm{P}=0.03$ \\
\hline
\end{tabular}


value of $0.04 \mu \mathrm{g} / \mathrm{L}$ [26] for cTnl was considered as the $99^{\text {th }}$ percentile of healthy players.

\section{Statistical analysis}

The data obtained was statistically treated by using the IBM Statistical Package of Social Sciences (IBM SPSS Statistics, v. 20.0 for WINDOWS). All the data are usually stated as the mean \pm SD values, except where stated in particular. For normal distribution Kolmogorov-Smirnov tests were used for analysis. A mixed model two-way ANOVA was performed with post-hoc Bonferroni tests (employed when appropriate) for the measurement of the effect of sampling time (pre, $5 \mathrm{~min}, 3$, 6 , and 24 h post-exercise). In the whole research work, bivariate Pearson's product moment correlation coefficients were used to assess the different variables. These parameters included the association between baseline cTnl, increases in cTnl, peak post-exercise value, and mean and max exercise HR during simulated gameplay. The values were taken to be significant when $p>0.05$.

\section{Results}

The results obtained (Table 2) from the shuttle run test of $20 \mathrm{~m}$ showed no difference between the groups for HRmax. However, the PFPs had lower mean HR than values for AFPs.

Table 2. Heart rate during the football match

\begin{tabular}{lc}
\hline & Mean HR (BPM) \\
\hline Professional football players $(\mathrm{n}=22)$ & $139 \pm 12.9$ \\
Amateur Football players $(\mathrm{n}=22)$ & $168 \pm 17.8$ \\
$\mathrm{P}$ value & $P<0.05$ \\
\hline
\end{tabular}

Figure 1 revealed, in all the subjects, an increased value of post-match cTnl in comparison to the base level of cTnl. From Figure 1, it is evident that 14 PFPs had high values for URL of cTnl. For post-match maximum cTnl value was observed at three hours in 34 subjects, the other 10 individuals reached a maximum at six hours. The study showed that the peak value of troponin I in plasma post-match was not related to the role of the player in the game. However, base level values were correlated with mean HR.

Additionally, for AFPs, a significant effect of groups was observed in the context of recovery cTnl as well as the baseline, which was lower than that of PFPs $(p=0.001)$. Furthermore, there was also dissimilarity in the data of the player groups for the highest after-exercise values of cTnl (AFP: median [range]; 0.029 [0.024-0.04]; PFP: 0.11 [0.02-0.3]).

\section{Discussion}

From the reviewed literature it can be confirmed that our research work is the first such work for investigating the cTnl "kinetics" post-football match, after the exercise is performed, in meticulous conditions, with separate groups of players distinguished by the status of the athlete and their age. The major findings from our studies were the variation in cTn, magnitude differences between baseline and post-football match cTn, and similarity of post-football match cTn response found in the professional players and amateur players.

Due to the application of fewer cTnl sampling intervals in the previous studies, several contradictory results have been reported for cTn release. However, in our study, a post-exercise cTnl increase was observed in every participant, which in general is contradictory

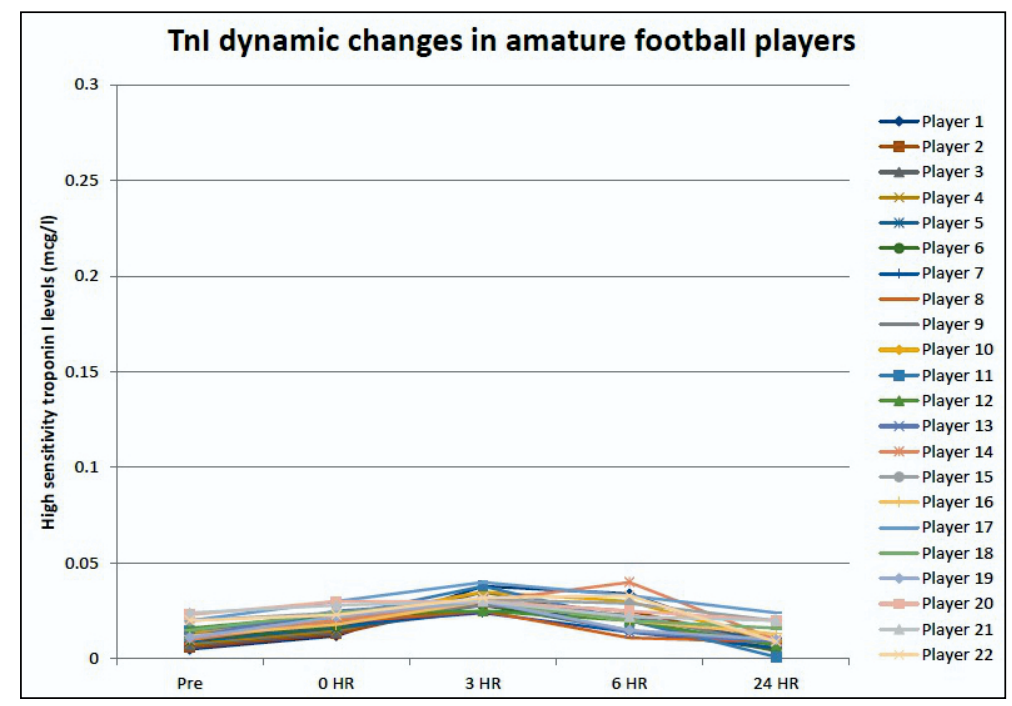

Figure 1. Tnl dynamic changes in amateur football players 


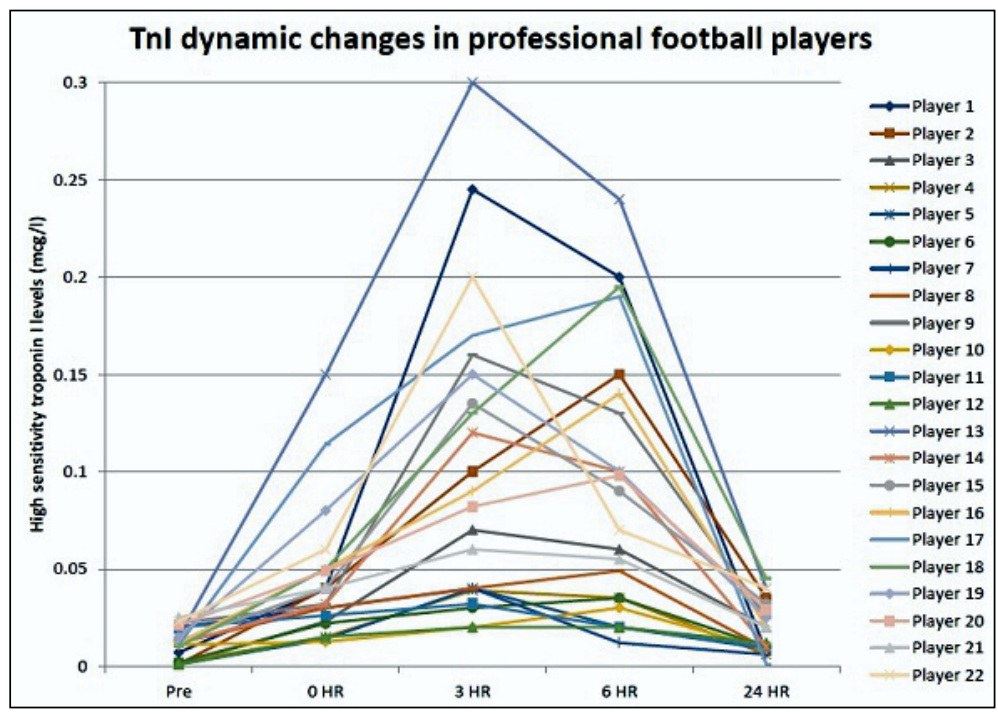

Figure 2. Tnl dynamic changes in professional football players

to the results in which no cTnl increase was observed, as reported by George et al. [25] and Rahnama et al. [24]. This difference can be better explained due to the use of a simple sampling plan. Our data is in accordance with results reported by Nie et al. [12], who also observed a cTn increase in the several hours after simulated gameplay. Therefore, this research work shows the importance of taking several samples during recovery to monitor the maximum post-exercise release values of cTn.

We report the individual variation of peak $\mathrm{cTnl}$ in $26 \%$ of subjects with only one individual having a cTnl value greater than the URL. However, this value is much lower than the reported percentages for other game exercises, such as for the long run marathon [28] or cycling [29]. Our findings confirm the diversity of cTnl release in peak time, and at that specific time the analysis suggests some degree of variance in "kinetics" of the cTnl appearance. It has been reported by previous researchers $[5,27]$ that when the magnitude of exercise is controlled, the exercise duration usually mediates the increase in cTnl or cTnT.

The results of many previous studies [17, 22] reported that post-exercise cTn peak is obtained within three to four hours post-exercise. However, our results are different in that most of the cTnl peak was observed six hours post-exercise, which affirms that many factors affect the peak post-exercise value, such as the intensity of exercise, duration, and mode of exercise. However, further studies are in demand to clear any such ambiguous data.

In cases of coronary syndromes, generally, the mode of cTn release and then clearance of CTn in post-exercise are at odds with the changes in the observed cTn. This could be due to the fact that after the exercise stimulus, post-exercise cTn levels may be related to a physiological response rather than a pathological response. It has been hypothesised that high-tension exercise usually results in an increase in the permeability of the membrane and causes membrane damage of the cell. This damage induces transient cytosolic leakage [30].

Among some reports of recent papers [14-18] it can be found that post-physical stress cTn release is more prominent in amateur players as compared to more physically fit players. This is because of the lower myocardial stress efficiency, which is due to the non-adaptability of the myocardial cells in amateur players, similar to the same adaptability mode of skeletal muscles [14, 15]. However, our results are in contradiction to this theory because higher post-physical stress values were expressed by PFPs than those of AFPs. During the simulated game, the lower HR and \%HRmax are in accordance with recent field-based studies with marathon runners [31] training under controlled mediation [21].

The PFPs had higher post-exercise cTnl values as compared to AFP values, which could be associated with changes in baseline cTnl. In previous studies [5] it was reported that there is a strong relation between the values of baseline and post-exercise cTnl release. Usually, no attention is given to the variation in baseline cTn values found in healthy people. It has been postulated that men and skilled athletes usually have larger hearts than women and lower trained players, respectively. This postulation has also been put forth by Mingels et al. [16], who observed very high hs-cTnT values. In the same way, we can rationalise the elevated concentration for both base-level and post-match cTnl in PFP; however, it cannot be clearly stated that the hypertrophied hearts of PFPs are larger than those of AFPs. Therefore, 
further research is needed to make clear the associations between the differences of exercise-related cTn values at baseline and the factors involved.

It is noteworthy for clinicians that $\mathrm{cTnl}$ release is not only related to highly intense exercises, because URL higher than cTnl can be observed even after intermittent exercises such as a sports game. Therefore, for clinicians it is important to consider any recent exercise activities in addition to any clinical signs or even in the absence of any symptoms but with positive cTn concentrations.

In this research work, we observed a diversified response of cTnl release among all players. Our results contradict past reports, which indicate a relation between professional players and cTnl plasma concentration after physical stress. Additionally, in our results, we postulate the relationship between physiological response after the exercise stimulus and changes in cTn release.

\section{Conclusions}

In our study, it is clear that intermittent exercise, such as a football game, causes an upsurge in cTnl plasma concentration. However, all the players had different cTnl values for peak and time-to-peak cTnl. Another major conclusion of the study is that the elite athletes showed higher values of cTn appearance as compared to amateur athletes, confirming the association of athlete status and cTn appearance.

\section{Conflicts of interest: None to declare Funding: None to declare}

Authors' contributions: Ali Aldujeli (main author), Kasparas Briedis (proof reading), Montazar Aldujeili (data collection), Auguste Stalmokaite (statistical analysis), Prof. Ramunas Unikas (conceived and designed the analysis)

\section{References}

1. Babuin L, Jaffe AS. Troponin: the biomarker of choice for the detection of cardiac injury. CMAJ. 2005; 173(10): 1191-1202, doi: 10.1503/cmaj/051291, indexed in Pubmed: 16275971.

2. Vasile VC, Babuin L, Ting HH, et al. Aborted myocardial infarction: is it real in the troponin era? Am Heart J. 2009; 157(4): 636-641, doi 10.1016/j.ahj.2008.12.005, indexed in Pubmed: 19332189

3. Baker P, Leckie T, Harrington D, et al. Exercise-induced cardiac troponin elevation: An update on the evidence, mechanism and implications. Int J Cardiol Heart Vasc. 2019; 22: 181-186, doi: 10.1016/j. ijcha.2019.03.001, indexed in Pubmed: 30963092.

4. Peretti A, Mauri L, Masarin A, et al. Cardiac Biomarkers Release in Preadolescent Athletes After an High Intensity Exercise. High Blood Press Cardiovasc Prev. 2018; 25(1): 89-96, doi: 10.1007/s40292-0170243-y, indexed in Pubmed: 29282696.

5. Legaz-Arrese A, George K, Carranza-García LE, et al. The impact of exercise intensity on the release of cardiac biomarkers in mara- thon runners. Eur J Appl Physiol. 2011; 111(12): 2961-2967, doi: 10.1007/s00421-011-1922-3, indexed in Pubmed: 21442162

6. Eijsvogels T, George K, Shave R, et al. Effect of prolonged walking on cardiac troponin levels. Am J Cardiol. 2010; 105(2): 267-272, doi: 10.1016/j.amjcard.2009.08.679, indexed in Pubmed: 20102930.

7. Michielsen EC, Wodzig WK, Van Dieijen-Visser MP. Cardiac troponin $T$ release after prolonged strenuous exercise. Sports Med. 2008; 38(5): 425-435, doi: 10.2165/00007256-200838050-00005, indexed in Pubmed: 18416595

8. Legaz-Arrese A, Carranza-García LE, Navarro-Orocio R, et al. Cardiac Biomarker Release after Endurance Exercise in Male and Female Adults and Adolescents. J Pediatr. 2017; 191: 96-102, doi: 10.1016/j. jpeds.2017.08.061, indexed in Pubmed: 29173327

9. Neilan TG, Januzzi JL, Lee-Lewandrowski E, et al. Myocardial injury and ventricular dysfunction related to training levels among nonelite participants in the Boston marathon. Circulation. 2006; 114(22): 2325-2333, doi: 10.1161/CIRCULATIONAHA.106.647461, indexed in Pubmed: 17101848

10. Stephenson C, McCarthy J, Vikelis E, et al. Effect of weightlifting upon left ventricular function and markers of cardiomyocyte damage. Ergonomics. 2005; 48(11-14): 1585-1593, doi: 10.1080/00140130500101114, indexed in Pubmed: 16338724

11. Wedin JO, Henriksson AE. Postgame elevation of cardiac markers among elite floorball players. Scand J Med Sci Sports. 2015; 25(4): 495-500, doi: 10.1111/sms.12304, indexed in Pubmed: 25109452.

12. Nie J, Tong TK, Shi Q, et al. Serum cardiac troponin response in adolescents playing basketball. Int J Sports Med. 2008; 29(6): 449-452, doi: 10.1055/s-2007-989236, indexed in Pubmed: 18004684

13. Scott JM, Esch BTA, Shave R, et al. Cardiovascular consequences of completing a 160-km ultramarathon. Med Sci Sports Exerc. 2009; 41(1): 26-34, doi: 10.1249/MSS.0b013e31818313ff, indexed in Pubmed: 19092706

14. Shephard RJ. Cardiac Troponin Increases Among Runners in the Boston Marathon. Yearbook of Sports Medicine. 2007; 2007: 149-151, doi: 10.1016/s0162-0908(08)70130-2.

15. Mehta R, Gaze D, Mohan S, et al. Post-exercise cardiac troponin release is related to exercise training history. Int J Sports Med. 2012; 33(5): 333-337, doi: 10.1055/s-0031-1301322, indexed in Pubmed: 22377942.

16. Mingels A, Jacobs L, Michielsen E, et al. Reference population and marathon runner sera assessed by highly sensitive cardiac troponin T and commercial cardiac troponin T and I assays. Clin Chem. 2009; 55(1): 101-108, doi: 10.1373/clinchem.2008.106427, indexed in Pubmed: 18988757

17. Nie J, George KP, Tong TK, et al. The influence of a half-marathon race upon cardiac troponin T release in adolescent runners. Curr Med Chem. 2011; 18(23): 3452-3456, doi: 10.2174/092986711796642625, indexed in Pubmed: 21756240.

18. Tian, Y., Changes in serum cardiac troponins following a $21-\mathrm{km}$ run in junior male runners. Journal of sports medicine and physical fitness, 2006. 46(3): p. ; 481

19. Nie J, George KP, Tong TK, et al. Effect of repeated endurance runs on cardiac biomarkers and function in adolescents. Med Sci Sports Exerc. 2011; 43(11): 2081-2088, doi: 10.1249/MSS.0b013e31821d4a82, indexed in Pubmed: 21502895

20. Nie J, Tong TK, George K, et al. Resting and post-exercise serum biomarkers of cardiac and skeletal muscle damage in adolescent runners. Scand J Med Sci Sports. 2011; 21(5): 625-629, doi: 10.1111/j.1600-0838.2010.01096.x, indexed in Pubmed: 20459466.

21. Bonetti A, Tirelli $F$, Albertini $R$, et al. Serum cardiac troponin $T$ after repeated endurance exercise events. Int J Sports Med. 1996; 17(4): 259-262, doi: 10.1055/s-2007-972843, indexed in Pubmed: 8814506.

22. König D, Schumacher $Y O$, Heinrich L, et al. Myocardial stress after competitive exercise in professional road cyclists. Med Sci Sports Exerc. 2003: 35(10): 1679-1683, doi: 10.1249/01.MSS.0000089248.37173. E7, indexed in Pubmed: 14523304

23. Leger, L. and C. Gadoury, Validity of the $20 \mathrm{~m}$ shuttle run test with $1 \mathrm{~min}$ stages to predict VO2max in adults. Canadian journal of sport sciences = Journal canadien des sciences du sport, 1989. 14(1): p. : 21-26.

24. Rahnama, N., Faramarzi, M., \& Gaeini, A. A. . Effects of Intermittent Exercise on Cardiac Troponin I and Creatine Kinase-MB. International journal of preventive medicine. 2011; 2(1): 20-23.

25. George KP, Dawson E, Shave RE, et al. Left ventricular systolic function and diastolic filling after intermittent high intensity team sports. $\mathrm{Br} J$ Sports Med. 2004; 38(4): 452-456, doi: 10.1136/bjsm.2003.004788, indexed in Pubmed: 15273183

26. Bagai A, Alexander KP, Berger JS, et al. Use of troponin assay 99th percentile as the decision level for myocardial infarction diagnosis. Am Heart J. 2017; 190: 135-139, doi: 10.1016/j.ahj.2017.04.016, indexed in Pubmed: 28760208. 
27. Fu F, Nie J, Tong TK. Serum cardiac troponin T in adolescent runners: effects of exercise intensity and duration. Int J Sports Med. 2009 30(3): 168-172, doi: 10.1055/s-0028-1104586, indexed in Pubmed: 19199217

28. Shave R, George KP, Atkinson G, et al. Exercise-induced cardiac troponin T release: a meta-analysis. Med Sci Sports Exerc. 2007; 39(12): 2099-2106, doi: 10.1249/mss.0b013e318153ff78, indexed in Pubmed: 18046180.

29. Skadberg $\varnothing$, Kleiven $\varnothing$, Bjørkavoll-Bergseth $M$, et al. Highly increased Troponin I levels following high-intensity endurance cycling may detect subclinical coronary artery disease in presumably healthy leisure sport cyclists: The North Sea Race Endurance Exercise Study (NEEDED) 2013. Eur J Prev Cardiol. 2017; 24(8): 885-894, doi: 10.1177/2047487317693130, indexed in Pubmed: 28186443.

30. Shave R, Oxborough D. Exercise-induced cardiac injury: evidence from novel imaging techniques and highly sensitive cardiac troponin assays. Prog Cardiovasc Dis. 2012; 54(5): 407-415, doi: 10.1016/j. pcad.2012.01.007, indexed in Pubmed: 22386291.

31. Gresslien T, Agewall S. Troponin and exercise. Int J Cardiol. 2016; 221 609-621, doi: 10.1016/.jijcard.2016.06.243, indexed in Pubmed: 27420587. 